\title{
RESEARCH PAPER \\ PHYSICAL PROPERTIES OF SOME NOBLE METAL COMPOUNDS FROM PAW-DFT CALCULATIONS
}

\author{
A. I. Popoola and S. S. Oluyamo \\ Department of Physics, Federal University of Technology, Akure. Nigeria. \\ Correspondence: ispopoola71@gmail.com
}

\begin{abstract}
The heats of formation, shear modulus, fracture toughness, density and melting points of compounds formed between some noble metals and aluminum, scandium, hafnium and zirconium were evaluated by the ab initio quantum mechanical projector augmented wave (PAW) calculation methods, using the Density Functional Theory (DFT) approach. Out of 24 compounds investigated, 17 are predicted to be thermodynamically feasible. In comparison with $\mathrm{Ni}{ }_{3} \mathrm{Al}, 13$ out of the 17 thermodynamically stable compounds are predicted with better hardness. Better fracture toughness and melting points are also predicted in favour of these compounds, suggesting their potentials for engineering applications under extreme conditions.
\end{abstract}

Keywords: Hardness, Poisson's ratio, bulk modulus, fracture toughness, melting point

\section{INTRODUCTION}

Nickel-aluminum alloys, especially $\mathrm{Ni}_{3} \mathrm{Al}$ have excellent fracture toughness's both at low and elevated temperatures (Aoki and Izumi, 1979) and this has encouraged its wide use in space and land based turbines. To improve operational efficiency and reduce emissions, modern turbines are required and designed to operate at high temperatures. $\mathrm{Ni}_{3} \mathrm{Al}$ melts at $1336^{\circ} \mathrm{C}$ (Massalski, 1990) and it is presently used near its melting point. As $\mathrm{Ni}_{3} \mathrm{Al}$ can't be improved further, both experimental (Cornish et al. 2003) and theoretical efforts (Popoola 2014; Popoola et. al. 2014) are ongoing to search for new class of alloys. Alloys based on the platinum metals are promising candidates because platinum metals are mostly resistant to oxidation or corrosion. They have higher melting points, and the fcc structure like nickel and some of them like platinum are highly ductile.

The purpose of this work is to theoretically evaluate some mechanical properties of alloys formed between some noble metals (i.e. Platinum (Pt), Iridium (Ir), Osmium (Os), Ruthenium $(\mathrm{Ru})$, Rhodium ( $\mathrm{Rh})$, Palladium $(\mathrm{Pd}))$ and 
aluminum (Al), scandium (Sc), hafnium (Hf) and zirconium $(\mathrm{Zr})$. These noble metals have been found to form solid solutions with other elements, resulting in different structure types (Massalski, 1990; Chauke et al. 2010). They have higher melting points than nickel, yet their elevated temperature strength and creep resistance remains a concern (Yamabe-Mitarai et al., 1996). The elements $\mathrm{Al}, \mathrm{Sc}, \mathrm{Hf}$ and $\mathrm{Zr}$ were theoretically alloyed with the noble metals in this investigation to among other things; achieve better fracture toughness and lower density. All calculations were done on the $\mathrm{L}_{2}$ structure (space group $\mathrm{Pm} 3 \mathrm{~m}$ ) in the same stoichiometry as $\mathrm{Ni}_{3} \mathrm{Al}$ (Fig. 1). From information available, this structure type is highly ordered and therefore, many defect types - defects of substitution, antiphase boundaries, super partial dislocations etc, should contribute to higher strength and better fracture toughness properties of the composite compound (Vasilev and Orlov. 1963; Schtremel, 1982). The results are expected to provide additional information regarding what is known and attempt to probe into the unknown. Particularly, comparison of data between these compounds and $\mathrm{Ni}_{3} \mathrm{Al}$ will help to determine the suitability or otherwise, of the use of these compounds under extreme conditions.

\section{CALCULATION METHOD}

All the calculations were done according to the Kohn and Sham, (1965) DFT formalism. The ground state energy $E$ of a system can be expressed as a function of the density $n$ as:

$$
E(n)=T_{g}(n)+E_{H}(n)+\mu_{n c}(n)+\int n(r) V_{w e}(r) d r
$$

$V_{\text {ext }}$ is an external potential energy. In terms of the expansion wave-functions $(\psi)$, the noninteracting kinetic energy $T_{s}(n)$ in equation 1 is expressed as:

$$
T_{g}(n)=\frac{\hbar^{2}}{2 m} \sum_{i} \int \psi_{i}{ }^{*}(r) \nabla^{2} \psi_{i}(r) d r
$$

The repulsive coulomb interaction between the electrons is given by the Hartree energy as:

$E_{H}(n)=\int \frac{n(r) n\left(r^{\prime}\right)}{r-r^{r}} d r d r^{\prime}$

In electronic structure calculations, $\mu_{x c}(n)$ is approximated. The local density approximation (LDA) and the generalized gradient approximation (GGA) are the most successful approximations. LDA uses a functional that depends lo-

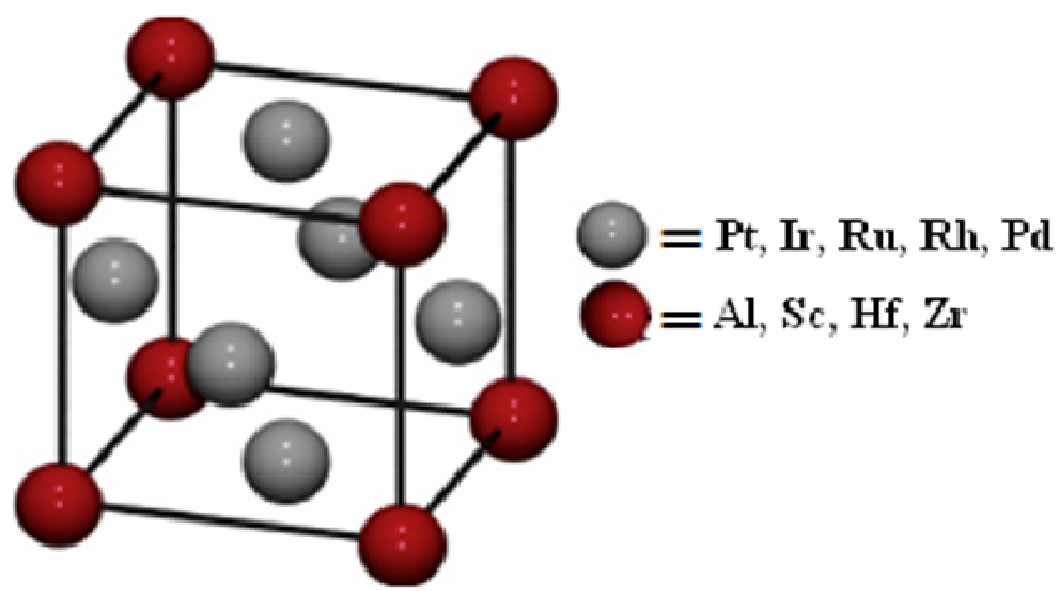

Fig. 1: The $\mathrm{L1}_{2}$ (space group Pm3m) crystal structure 
cally on the density and it has the form;

$\mu_{w e}^{L D A}[n(r)]=\int n(r) \epsilon_{w e}[n(r)] d r$

For practical calculations, the actual numerical values of $\epsilon_{x c}$ for many densities are obtainable from the many body perturbation theory (Herdin and Lundqvist, 1971) and the Monte Carlo method (Ceperley and Alder, 1980). The GGA gives an improvement on the LDA including gradient corrections. It is achieved with the addition of an enhancement factor $F_{x c}[n(r)$, $\nabla n(r)]$ which directly modifies the LDA energy as:

$\mu_{x c}^{G Q A}[n(r)]=\int n(r) \epsilon_{x c}[n(r)] d r F_{x c}\left[n(r), \bar{\nabla}\left(r^{2}\right)\right]$

The most popular enhancement factor $F_{x c}$, are those by Becke (1988) (known as B88), Perdew and Wang (1991) (known as PW91) and the Perdew, Burke and Ernzerhof (1996) (known as PBE96). The GGA has the advantage of correcting the over-biding tendency of the LDA.

Equation 1 was solved with the VASP computer code (Kresse and Furthmüller, 1996). The functional, $\mu_{x c}(n)$ was obtained with the generalized gradient approximation (GGA) (Perdew et al., 1996). During the wave-function expansions, a "high" precision was sought in the calculation of the kinetic energy. During the selfconsistency procedure, integration over the Brillouin zone was performed according to the Monkhorst and Pack (1976) scheme. Forces on atoms were less than $0.001 \mathrm{eV} / \AA$ during geometrical optimizations. All the three elastic constants $\left(\mathrm{c}_{11}, \mathrm{c}_{12}, \mathrm{c}_{44}\right)$ required to describe a cubic structure was evaluated using the approach in Mehl et al. (1990). The bulk modulus (B) and the shear modulus $(\mathrm{G})$ were evaluated according to the Hill (1952) averages and the expressions are given in equations 5 and 6 .

$B=\frac{\left(c_{11}+2 c_{12}\right)}{3}$
$G=\frac{1}{2}\left[\left(\frac{\left.c_{11}-c_{12}-3 c_{44}\right)}{5}\right)+\left(\frac{5\left(c_{11}-c_{12}\right) c_{44}}{\left[4 c_{44}+3\left(c_{11}-c_{12}\right)\right.}\right)\right]$

The Poisson's ratio ( $v)$, was calculated from the relation:

$v=\frac{3 B-2 G}{2(3 B+G)}$

From the ground state total energy in Equation 1 , the heats of formation $\left(\Delta H_{\mathrm{f}}\right)$ was evaluated and defined (Grimvall, 1986; Staple et al., 2001) as:

$\Delta H_{f}^{\phi}\left(A_{m} B_{n}\right)=\frac{1}{n+n} E_{A_{m}}^{\phi} B_{n}-\left[\frac{m}{m+n} E_{A}^{\phi}+\frac{n}{m+n} E_{B}^{n}\right]$

where $E^{\phi} A_{m}{ }^{B} n$ is the total energy of $A_{m} B_{n}$ compound with $\phi$ structure, $E_{A}^{\Phi}$ is the total energy per atom of $A$ with $\Phi$ structure and $E_{B}^{\varphi}$ is the total energy per atom of $B$ with $\varphi$ structure. From the elastic moduli $c_{i j}$, the melting point (MP) of each alloy was estimated. This can be achieved (Blackman, 1951; Fine et al. 1984) by fitting the equilibrium value of $c_{i j}$ to equation 6 .

$\mathrm{T}_{m}=553 K+(591 K / M b a r) c_{11} \pm 300$

\section{RESULTS AND DISCUSSION}

The results of all the calculations are shown in Figs. 2 - 6. According to Fig. 2, the formation of $\mathrm{L1}_{2}-\mathrm{Ru}_{3} \mathrm{Al}, \mathrm{L1}_{2}-\mathrm{Ru}_{3} \mathrm{Hf}, \mathrm{L1}_{2}-\mathrm{Ru}_{3} \mathrm{Zr}, \mathrm{L1}_{2}$ $\mathrm{Os}_{3} \mathrm{Al}, \mathrm{L}_{2}-\mathrm{Os}_{3} \mathrm{Sc}, \mathrm{L1}_{2}-\mathrm{Os}_{3} \mathrm{Hf}$ and $\mathrm{L1}_{2}-\mathrm{Os}_{3} \mathrm{Zr}$ are not thermodynamically feasible. The $\Delta H_{f}$ values for these compounds are either positive or too small to support their formation. An assessment of available thermodynamic databases Massalski, (1990) showed that $\mathrm{Pt}_{3} \mathrm{Sc}, \mathrm{Ir}_{3} \mathrm{Sc}$, $\mathrm{Ir}_{3} \mathrm{Zr}, \mathrm{Ir}_{3} \mathrm{Hf}, \mathrm{Rh}_{3} \mathrm{Sc}, \mathrm{Rh}_{3} \mathrm{Zr}, \mathrm{Rh}_{3} \mathrm{Hf}, \mathrm{Pd}_{3} \mathrm{Sc}$ and $\mathrm{Ru}_{3} \mathrm{Sc}$ would exist in the $\mathrm{L1}_{2}$ phase at ground state, agreeing with the results. Both the $\mathrm{L}_{2}$ and $\mathrm{DO}_{24}$ structure have been reported in $\mathrm{Pt}_{3} \mathrm{Zr}$, $\mathrm{Pt}_{3} \mathrm{Hf}, \mathrm{Pd}_{3} \mathrm{Zr}$ and $\mathrm{Pd}_{3} \mathrm{Hf}$ (Elliot, 1968). The result predicts that the formation of solid solution would be more favoured between the platinum 


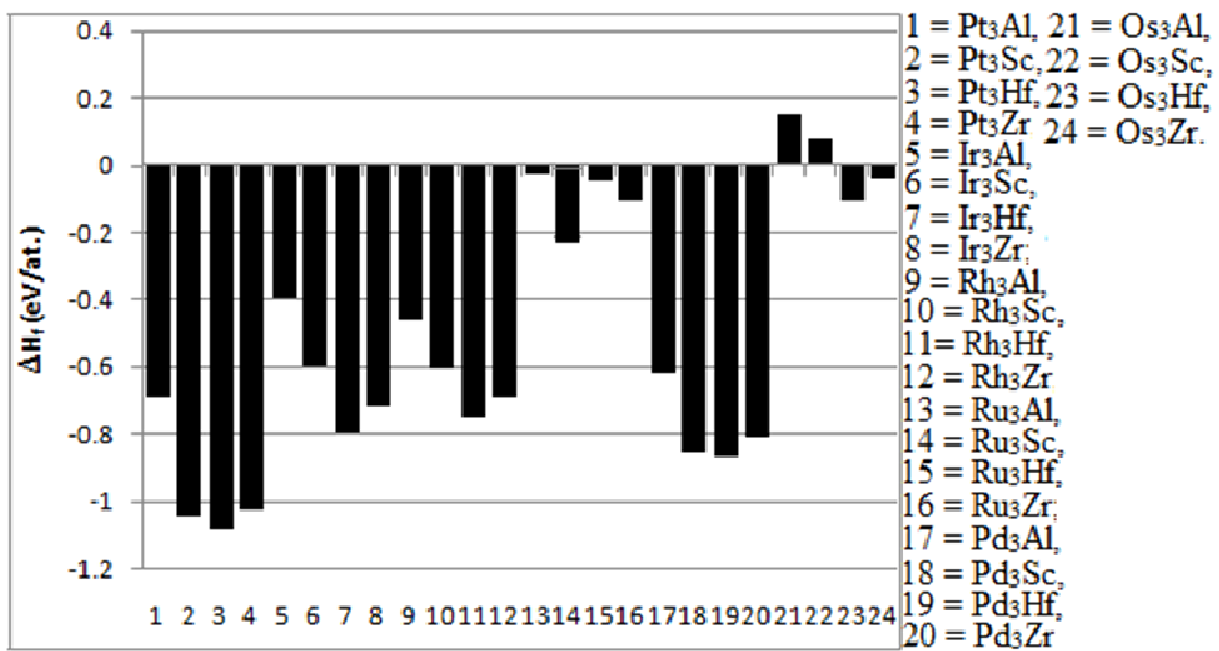

Fig. 2: Heats of formation chart for some platinum metal alloys in the $\mathrm{L1}_{2}$ structure

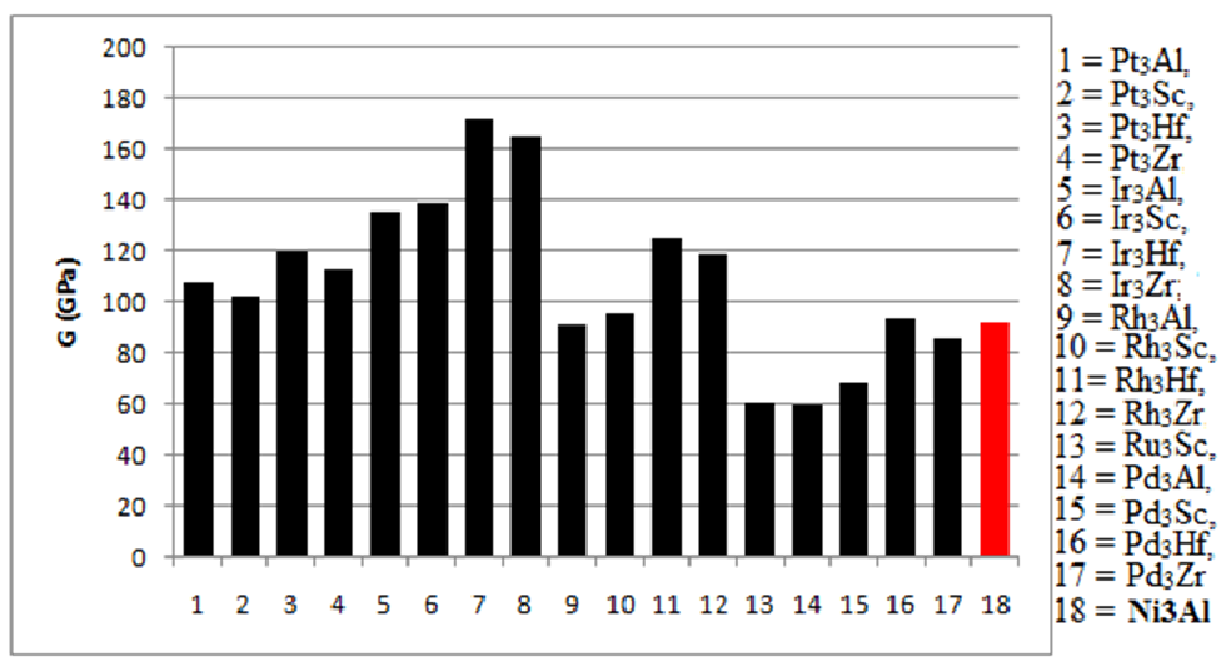

Fig. 3: Comparison between the shear modulus of $\mathrm{Ni}_{3} \mathrm{Al}$ and some platinum metal alloys in the $\mathrm{L1}_{2}$ structure

metals and hafnium, followed by scandium, zirconium and aluminum.

For any material to be of engineering value, it must possess an acceptable level of hardness. The hardness of a material has been correlated to its shear modulus (Teter, 1998; Leger et al., 2001). Comparison between the calculated 


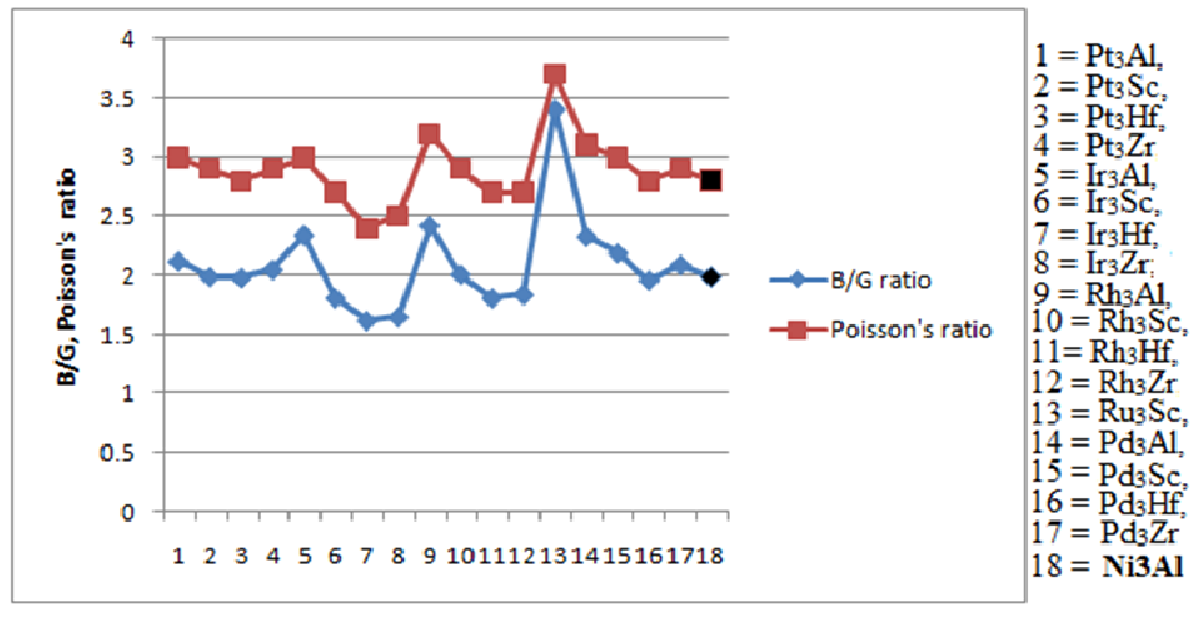

Fig. 4: Comparison of $\mathrm{B} / \mathrm{G}$ and the Poisson's ratios between $\mathrm{Ni}_{3} \mathrm{Al}$ and some platinum metal alloys in the $\mathrm{L1}_{2}$ structure. The Poisson's ratios are magnified by a factor of 10

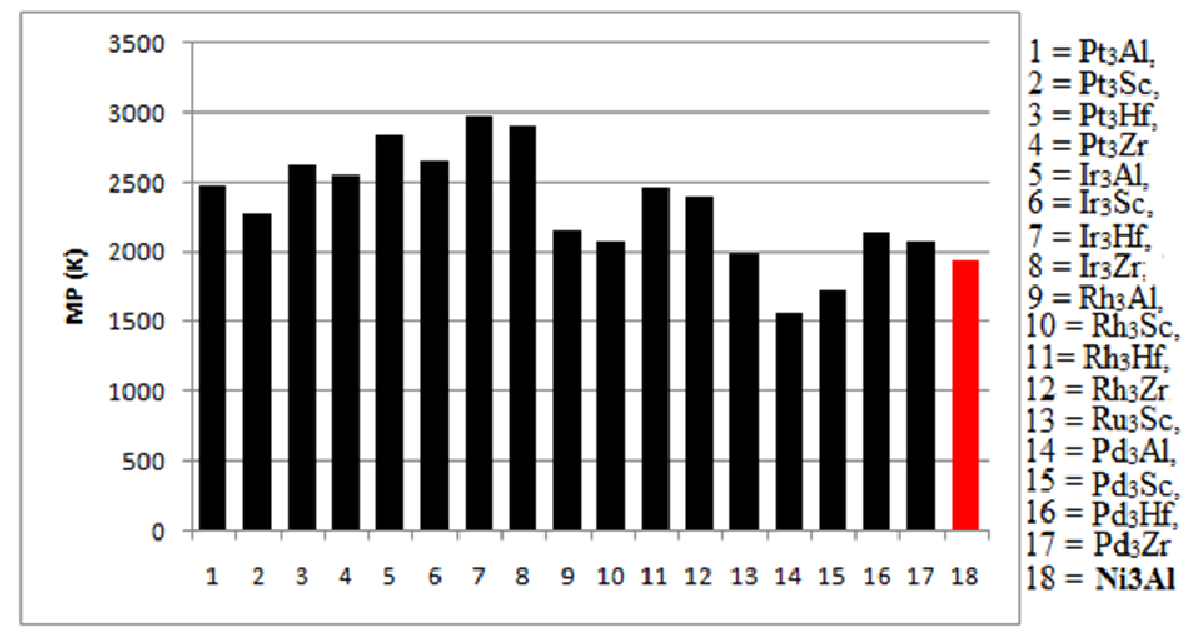

Fig. 5: Comparison of the melting point between $\mathrm{Ni}_{3} \mathrm{Al}$ and some platinum metal alloys in the $\mathrm{L1}_{2}$ structure

shear modulus of $\mathrm{Ni}_{3} \mathrm{Al}$ and all the compounds predicted to be thermodynamically feasible in Fig. 2 are shown in Fig. 3. With the exception of $\mathrm{L1}_{2}-\mathrm{Ru}_{3} \mathrm{Sc}, \mathrm{L1}_{2}-\mathrm{Pd}_{3} \mathrm{Al}, \mathrm{L1}_{2}-\mathrm{Pd}_{3} \mathrm{Sc}$ and $\mathrm{L1}_{2}-$ $\mathrm{Pd}_{3} \mathrm{Zr}$, all the other compounds are predicted to have higher hardness than $\mathrm{Ni}_{3} \mathrm{Al}$. The fracture toughness of a material had been correlated to its $\mathrm{B} / \mathrm{G}$ ratio and/or the Poisson's ratio (Pugh, 1954; Frantsevich et al., 1982). According to the results in Fig. 4, $\mathrm{L1}_{2}-\mathrm{Ru}_{3} \mathrm{Sc}$ is predicted to 


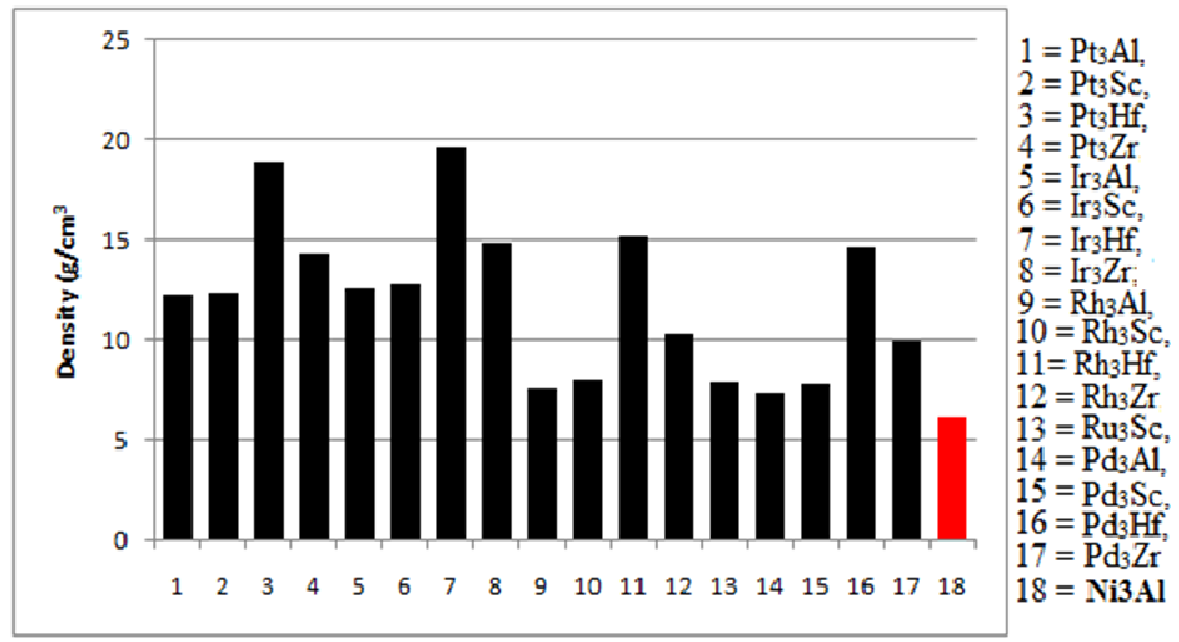

Fig. 6: Comparison of the density between $\mathrm{Ni}_{3} \mathrm{Al}$ and some platinum metal alloys in the $\mathrm{L1}_{2}$ structure

have the highest fracture toughness, while $\mathrm{L}_{2}-$ $\mathrm{Ir}_{3} \mathrm{Hf}$ is predicted with the least fracture toughness.

The result obtained on the melting points is shown in Fig. 5. With the exception of $\mathrm{L1}_{2}-$ $\mathrm{Pd}_{3} \mathrm{Al}$ and $\mathrm{L1}_{2}-\mathrm{Pd}_{3} \mathrm{Sc}$, all the other compounds are predicted to have higher melting points than $\mathrm{Ni}_{3} \mathrm{Al}$. In addition to high melting points, good fracture toughness and an acceptable level of hardness, most materials for engineering applications are required to have low density, especially in applications such as space-bound turbines. In comparison with $\mathrm{Ni}_{3} \mathrm{Al}$, the calculated density of all the compounds investigated is shown in Fig. 6. With the exception of $\mathrm{L1}_{2}-$ $\mathrm{Rh}_{3} \mathrm{Al}, \mathrm{L1}_{2}-\mathrm{Rh}_{3} \mathrm{Sc}, \mathrm{L1}_{2}-\mathrm{Ru}_{3} \mathrm{Sc}, \mathrm{L1}_{2}-\mathrm{Pd}_{3} \mathrm{Al}, \mathrm{L1}_{2}-$ $\mathrm{Pd}_{3} \mathrm{Sc}$ and $\mathrm{L1}_{2}-\mathrm{Pd}_{3} \mathrm{Zr}$, the density of all the other compounds are predicted to be above 10 .

\section{CONCLUSION}

The physical properties of some noble metal compounds in the stoichiometry $\mathrm{M}_{3} \mathrm{X}(\mathrm{M}=\mathrm{Pt}$, $\mathrm{Ir}, \mathrm{Os}, \mathrm{Rh}, \mathrm{Pd}, \mathrm{Ru}$ and $\mathrm{X}=\mathrm{Al}, \mathrm{Sc}, \mathrm{Hf}, \mathrm{Zr}$ ) were evaluated within the quantum mechanical den- sity functional theory framework. When compared with $\mathrm{Ni}_{3} \mathrm{Al}$, most of the alloys investigated showed better physical properties except in density. Many of the compounds, especially those with conflicting structures (i.e. $\mathrm{Pt}_{3} \mathrm{Zr}$, $\mathrm{Pt}_{3} \mathrm{Hf}, \mathrm{Pd}_{3} \mathrm{Zr}$ and $\mathrm{Pd}_{3} \mathrm{Hf}$ ) are suggested for further studies. Additional information, particularly regarding bonding, phase stability etc, can be obtained from calculation such as the Density of States (DOS), electron localization function, band structure and charge density results. With most properties investigated and predicted to be better for the noble metal compounds than $\mathrm{Ni}_{3} \mathrm{Al}$, these materials should play a significant role in the development of new class of superalloys.

\section{ACKNOWLEDGEMENT}

We would like to thank the Centre of Excellence for Strong Materials, University of the Witwatersrand and the Department of Science and Technology, Republic of South Africa for the use of their computing facilities.

\section{REFERENCES}

Aoki, K. and Izumi, O. (1979). Flow and frac- 
Mechanical properties of alloys formed between some noble metals... 53

ture behaviour of $\mathrm{Ni}_{3}(\mathrm{Al}-\mathrm{Ti})$ single crystals tested in tension. Journal of Materials Science, 14: 1800-1806.

Becke, A. D. (1988). Density-functional exchange-energy approximation with correct asymptotic behavior. Physical Reviews A, 38: $3098-3100$.

Blackman, M. (1951). On the calculation of characteristic temperatures from the Elastic constants. Philosophical Magazine, 42: 14411442 .

Ceperly, D. M. and Alder, B. J. (1980). Ground State of the Electron Gas by a Stochastic Method. Physical Review Letters, 45: 566569.

Chauke, H. R., Minisini, B., Drautz, R., Nguyen-manh, D., Ngoepe, P. E. and Pettifor, D. G. (2010). Theoretical investigation of the $\mathrm{Pt}_{3} \mathrm{Al}$ ground state. Intermetallics, 18: $417-421$.

Cornish, L. A., Fischer, B. and Völkl, R. (2003). Development of Platinum-GroupMetal Based Superalloys for HighTemperature Use. MRS Bulletin, 28: 632 638.

Elliot, R. P. (1968). Constitution of binary alloys. New-York: McGraw-Hill.

Fine, M. E., Brown, L. D. and Marcus, H. L, (1984). Elastic Constants versus Melting Temperature in Metals. Scripta Metallurgical, 18: 951- 956.

Frantsevich, I. N., Voronov, F. F. and Bokuta, S. A. (1982). Handbook of Elastic Constants and Moduli of Metals and Insulators. Kievl: Naukova Dumka.

Grimvall, G. (1986). Thermophysical Properties of Materials. Amsterdam: NorthHolland.
Hedin, L. and Lundqvist, B. I. (1971). Explicit local exchange-correlation potentials. Journal of Physics C: Solid State Physics, 4: 2064 -2085 .

Hill, R., (1952). The Elastic Behaviour of a Crystalline Aggregate. Proc. Phys. Soc., 65: $349-354$.

Kohn, W. and Sham, L. J. (1965). Selfconsistent equations including exchange and correlation effects. Physical Reviews A, 140: $1133-1138$.

Kresse, G. and Furthmüller, J. (1996). Efficiency of ab-initio total energy calculations for metals and semiconductors using a planewave basis set. J. Comp. Mat. Sci., 6: 15 50 .

Leger, J. M., Djemia, P., Ganot, F., Haines, J., Pereira, A. S. and Da Jornada, J. A. H. (2001). Hardness and elasticity in cubic ruthenium dioxide, Applied Physics Letters, 79: $2169-2171$.

Massalski, T. B. (1990). Binary Alloy Phase Diagrams. Ohio: ASM International.

Mehl, M. J., Osburn, J. E., Papacostantopoulos, D. A. and Klein, B. M. (1990). Structural Properties of Ordered High-MeltingTemperature Metallic Alloys from First Principles Total Energy Calculations. Physical Reviews B, 41:10311-10323.

Monkhorst, H. J. and Pack, J. D. (1976). Special points for Brillouin-zone integrations. Physical Reviews B, 13:5188-5192.

Perdew, J. P and Wang, Y. (1992). Accurate and simple analytic representation of the electron-gas correlation energy. Physical Review B, 45 (23) : 13244-13249.

Perdew, J. P., Burke, K. and Ernzerhof, M. (1996). Generalized gradient approximation made simple. Physical Review Letters, 77: 


\section{Popoola and Oluyamo}

$3865-3868$.

Popoola, A. I. (2014): Trends in the compressibility of $\mathrm{X}_{3} \mathrm{Al}$ ( $\mathrm{X}=\mathrm{Pt}$, Os, Ru, Ir, Rh) compounds from $0-2000 \mathrm{~K}$. Ife Journal of Science. 16: $19-22$.

Popoola, A. I., Chown, L. H. and Cornish, L. A. (2014). Theoretical Investigations of $\mathrm{Pt}_{3} \mathrm{X}$ (X = Al, Sc, Hf, Zr) Ground State. Turkish Journal of Physics, 38: 11-16.

Pugh, S. F. (1954). Relations between elastic moduli and plastic properties of polycrystalline pure metals. Philosophical Magazine, 45: $823-843$.

Schtremel, M. A. (1982). Firmness of alloys; Defects of a lattice. Moscow: Metallurgy.
Stample, C., Mannstadt, W., Asahi, R. and Freeman, A. J. (2001). Electronic structure and physical properties of early transition metal mononitrides: Density-functional theory LDA, GGA, and screened-exchange LDA FLAPW calculations. Physical Reviews B,63:155106-155116.

Teter, D. M. (1998). Computational Alchemy: The Search for New Superhard Materials. MRS Bull., 23: 22 - 27.

Vasilev, L. I. and Orlov, A. N. (1963). Phys. of metals and metall., 15.

Yamabe-Mitarai, Y., Ro, Y., Maruko, T. and Harada, H. (1996). Ir-Base Refractory Superalloys for Ultra-High Temperatures. Scripta Materiala, 35: $211-215$. 